\title{
Towards operational forecasting of agricultural soil water in Australia
}

\author{
$\underline{\text { R.M. Argent }}^{\mathrm{a}}$, A.W. Western ${ }^{\mathrm{b}}$ and A. Lill ${ }^{\mathrm{c}}$ \\ ${ }^{a}$ Bureau of Meteorology, Docklands, Victoria, Australia \\ ${ }^{b}$ Department of Infrastructure Engineering, The University of Melbourne, Victoria, Australia \\ ${ }^{c}$ Bureau of Meteorology, Canberra, ACT, Australia \\ Email:R.Argent@bom.gov.au
}

\begin{abstract}
Australia has large and diverse agricultural industries, in addition to a highly variable climate. Recent government policy has focussed on increasing farm productivity. One of the challenges for achieving this, especially for rain-fed agriculture, is improving local-scale information on current and forecast future soil water status. Reliable soil water forecasts will allow users to better predict likely future water availability and make better informed farming decisions over timescales from days to seasons. This paper explores the state-of-the-art of the components that need to be brought together to transition our research knowledge into operational soil water forecasts, and the challenges that lie therein.
\end{abstract}

Achieving operational agricultural soil water forecasts requires bringing together a diverse range of components, including:

Long-term soil water monitoring - high quality profile soil water monitoring datasets extend to 10 years for some sites, while remote sensing data for surface $(<5 \mathrm{~cm})$ soil water extends to fifteen years and beyond. These provide fundamental data against which soil water simulation 'hindcasts' and forecasting methods can be developed and tested.

Remote sensing and data assimilation - the resolution, frequency, quantity, and inter-product consistency of remote observations relevant to modelling of soil water is increasing. This includes dedicated satellites for soil water. Current technology, techniques, and infrastructure provide the capability to assimilate such data into soil water models on an ongoing operational basis. These datasets can improve both forecasting methods, by bounding hindcast predictions, and operational forecasts, by providing good initial conditions for predictions.

Rainfall and temperature forecasts - multi-week to multi-season climate forecasts are a critical driver of soil water forecasts. These are currently produced weekly as daily ensemble (probabilistic) forecasts over a $250 \mathrm{~km}$ grid out to 270 days ahead, with significantly diminishing skill (accuracy) beyond about 3 months. Limited research to increase the resolution and skill of these forecasts is underway, with a focus on agricultural applications. Operational improvements, including increased spatial resolution, will occur in the near future.

Soil water modelling - Operational earth system forecasting models and crop growth models are both capable of producing soil water as outputs. Each operates at extremes of the global spatial scale (landscape versus point-scale). Their skill to produce explicit probabilistic soil water forecasts as ensembles has yet to be fully evaluated. There is also a challenge to determine the best approaches to take advantage of, and integrate, rainfall forecasts, remote observations, and local scale soil and management information.

Local scale inputs - The ability of soil to store water and make it available to plants varies widely. Local information on soil type and properties, soil water observations, and crop management increases the relevance of forecasts. They can also increase forecast accuracy by tuning the down-scaling of broadscale forecasts to local conditions. Farm-scale monitoring and communication technologies have now matured to the point where they offer significant potential as a key input to the localisation of forecasts.

Integrating and maturing these components in a structured and strategic manner is required for us to achieve the goal of useful operational seasonal forecasting of agricultural soil water in Australia.

Keywords: Soil water forecasting, seasonal climate outlook, soil water modelling 


\section{INTRODUCTION}

Soil water is the limiting climatically controlled (ie. radiation, temperature, soil water) resource for plant growth for nearly all the Australian continent (Nemani et al., 2003). Reliable soil water forecasts will allow users to better predict likely future water available for primary production. Forecasts will allow for more informed decisions to manage this limited resource, and to manage the risks stemming from reduced supply or oversupply. This will lead to more profitable, agile farm business and supply chains. However, we are some distance away from operational forecasting of soil water. This paper presents a brief overview of components that need to be brought together to transition our research knowledge into operational soil water forecasts, and the challenges that lie therein.

The recent Australian Government white paper on agricultural competitiveness recognises the central role that water and its effective management has, stating that "Managing water resources sensibly, equitably and sustainably to ensure our agricultural competitiveness into the future is an important aspect of the Commonwealth's leadership role in the nation's water reform agenda" (Commonwealth of Australia, 2015)

Improved water management is vitally important to Australia given annual farm production values of $\$ 50.8$ billion in 2013-14 (Australian Bureau of Statistics, 2015), and the effects on agricultural profitability of variations in rain-fed and irrigated water supply.

Water supply is most accurately reflected as soil water, and for many decisions, particularly the fraction that is available to crops. To understand future water supply constraints farmers currently rely on estimates of current soil water storage (in-situ observation, modelling, intuitive inference from recent weather), relatively broad scale climate and rainfall forecasts, and an understanding of future demand as crop growth potential gained through experience or simulation models. This is often interpreted in the context of other user-specific information such as soil attributes, pests, fertiliser, irrigation, and paddock history. Such approaches are prone to high error and present a significant opportunity for targetted improvement.

\subsection{Agricultural soil water in context}

To help manage their businesses, farmers seek better understanding of current and future soil water in the context of previous or analogue seasons. They also desire information that is relevant for their own farm systems and soil types such as:

- Better situational assessment - accurate assessments of changing soil water conditions from recent rainfall events.

- Improved prediction - and refined rainfall (or lack of rainfall) prediction.

- Crop response - forecast response for crops/pastures including yield prediction.

Currently, farmers rely on rainfall forecasts or past experience to predict future changes in farm soil water balances. Many tools applied by farmers can also predict soil water through crop growth models, often forced by rainfall data. What further information or capability will operational soil water forecasting add over that offered by high quality rainfall forecasts?

\subsection{The value of soil water forecasts}

Operational soil water forecasts that take advantage of finer resolution remote sensing, soils information and forecast ensembles could provide:

- $\quad$ higher predictability of plant water availability than forecast rainfall due to the predictive power of soil memory and the more direct relationship between soil water and plant growth;

- independent validation of soil water monitoring/sensing and crop model forecasts, or additional information to calibrate and or assimilate into future growth crop models;

- capability to apply farm-relevant soil water information within extensive agricultural systems where intensive monitoring or modelling is impractical or of high cost;

- $\quad$ potential to simplify some of the parameterisation of complex crop growth models - especially where detailed soil properties and moisture monitoring is unavailable, unreliable or cost prohibitive;

- improved and more accessible information for applications where soil water forecasts are required, but site-specific soil water modelling is not; and

- farm-relevant soil water forecasts with lead times beyond the current crop cycle, giving farmers better understanding of current conditions and more time to make alternative management decisions.

Developing, testing and delivering operational soil water forecasting comes with many challenges and opportunities, such as: 
1. Soil water and related information is available as either point-scale or very broad scale interpolated data. Spatial re-scaling (in both directions) is needed to best utilise current data sources for soil water forecasting.

2. Integrating high frequency observations of near-surface soil water to the full soil profile for a wide range of soil types and crop systems.

3. How to best "ground-truth" forecasts using multiple lines of evidence at different scales- verifying that the forecast soil water matches remote sensing of soil water data via satellite, crop model simulations, and in-situ measurements on the ground.

4. Determining where in the wider 'ecosystem' of modelling and decision support tools such advances in fine-resolution information on soil type and remote sensed data is most efficiently utilised to model soil water.

5. How to best utilise soil water forecasts to improve sector wide and on-farm decision making.

\section{OPERATIONAL SOIL WATER FORECASTING COMPONENTS - STATE OF THE ART}

Addressing the challenges and meeting the promise of operational soil water forecasting requires integration of a number of components, all of which have developed and matured over the last decade.

The components and their integration are shown in Figure 1. Satellite and surface observations provide the soil water history used for the hindcasts that support model design and calibration, as well as current soil water status as an initial model state. When added to soil data, these provide key inputs to the land surface process or point-scale crop models used to produce soil water forecasts.

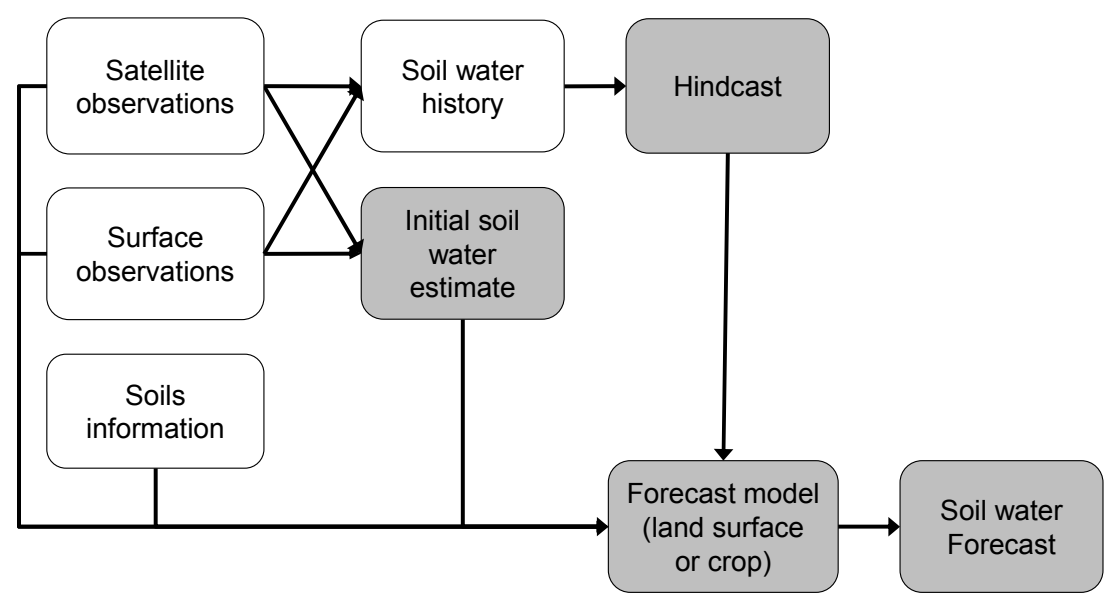

Figure 1. Components in soil water forecasting.

The state of the art of these components in Australia was considered in a two-day workshop held in Melbourne, Australia in February 2015, giving rise to the following assessments.

\subsection{Ground-based observations}

Significant ground-based soil water monitoring is going on, for a variety of purposes and using a range of techniques. The primary differences between techniques, which span from cosmic ray sensors to direct soil measurement, are in depth and spatial extent of measurement. There is also a range of monitoring record lengths available, with the longest being of the order of a decade (Smith et al., 2012). The Murrumbidgee area has attracted considerable attention, although other sources include South-West Victoria, Western Australia, Tasmania (e.g. via Southern Farming Systems) and Queensland (e.g. via University of Southern Queensland). The challenges of getting good depth and spatial coverage are well known to the research community, and monitoring technologies and techniques, such as vehicle-mounted, are the subject of research and development. There are long-term networks internationally that could provide learnings. Challenges for the future include the absence of an extensive, coherent national long term monitoring program, the lack of standardised monitoring and data protocols, and the need for further inter-comparison analysis between methods. 


\subsection{Remote sensing}

There has been $\sim 30$ years of remote sensing history related to soil water, with resolution and instrument coverage continuing to increase. The capabilities (in terms of native and product resolution and characteristics) of different satellite series are known. The challenges in accuracy, errors, downscaling, resampling and biases in regards to estimating agricultural soil water are manyfold, although somewhat understood due to considerable work on comparisons against in-situ soil water data (e.g. Crow et al., 2012). Standardisation across platforms to produce consistent output is a challenge, although recent signal processing approaches for data merging show promise (Su and Ryu, 2015). Vegetation can limit efficacy, and large footprints and sampling depth remain as issues. A key to understanding the utility of various sensors for the purposes of agricultural soil water analysis is to understand what nature of soil water product is actually required.

\subsection{Assimilation, bias correction and modelling}

It is desirable to assimilate observation data into models to predict agriculturally-relevant soil water. Root zone soil water estimates can be improved through assimilation, although getting the right spatial extent is a challenge and performance reduces with depth. Examples of assimilation include surface process and runoff modelling, although experience in assimilating remotely-sensed surface soil water for crop growth is less extensive. Relevant models that could assimilate shallow soil water include CABLE (CABLE Community, 2015), the AWRAMS landscape water balance model (Hafeez et al., 2015) and ACCESS numerical weather/climate prediction model (The Collaboration for Australian Weather and Climate Research, 2015). There is a need for product inter-comparisons to understand strengths and weaknesses of different approaches, supported by ground-truthing of estimates.

\subsection{Forecasting options}

Accurately estimating current amounts of plant-available water and likely future amounts are both of interest and value. Challenges include the level of uncertainty across the time frames of decisions, and relating broad scale $(5-250 \mathrm{~km})$ modelling and forecasts to local scale paddocks, soils and crops. Potential end users need to be 'primed' about the possible information products, and end user needs must drive development, including consideration of where and how an operational forecasting service would sit alongside the tools already accessed and used by farmers and advisors.

\subsection{Operational methods}

There is a range of weather and climate models in operation that include land surface schemes which cover soil water to a greater or lesser degree. There also exist crop/agronomic models that predict yield and which take into account key dynamics such as nutrient status, crop growth, water use and changes in root depth. The pros and cons of alternative approaches will need to be compared as part of developing operational soil water forecasting, including the connection to other modelling purposes, such as drought information.

These brief assessments of the state-of-the-art clearly indicate that the time is ripe to investigate, understand and overcome the challenges in transitioning our research knowledge into an operational service.

\section{DEVELOPING AND RUNNING AN OPERATIONAL SERVICE}

Creating and maintaining an operational soil water forecasting service lies a significant distance from the desktop activities often used in research and development. Figure 2 provides a high level evaluation of the level of maturity of the four parts of an operational service:

1. An operational application which can be tested, proven and used to gain user feedback;

2. Research to generate new knowledge used to improve the service;

3. Development and maintenance to create and update operational services; and

4. Running a reliable, accessible and functional operational service

A colour indicator of status is provided, where 'green' indicates a mature level of knowledge or operation, 'amber' indicates a level that has issues, most of which are known and able to be overcome, and 'red' indicates an immature level of development. 


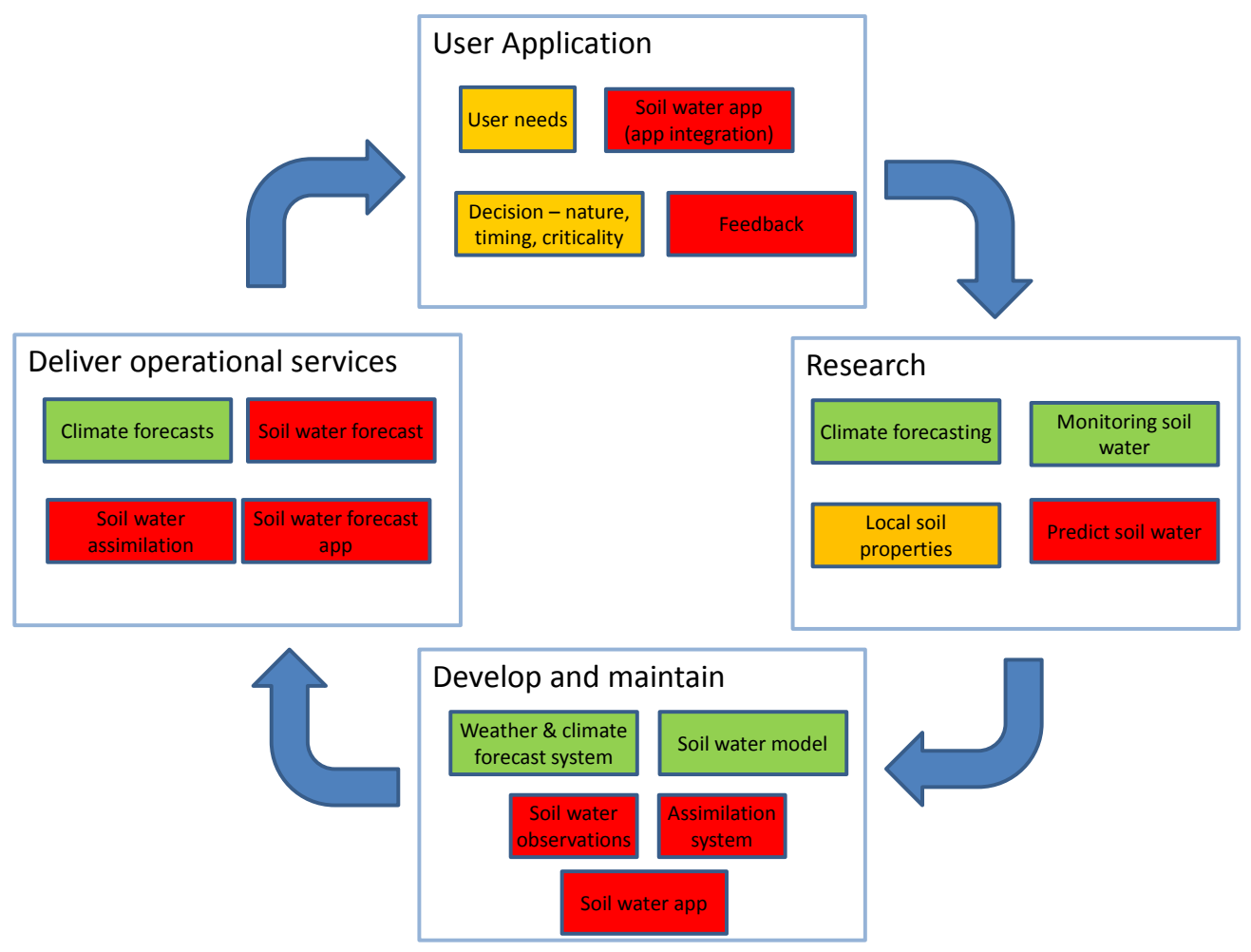

Figure 2. Maturity level of elements of an operational system.

\subsection{The user application}

User needs (status: amber) are reasonably well understood at a high level, although many agricultural producers do not explicitly use soil water forecasts. Therefore, user needs must become more clearly defined in response to prototype services, and new needs may develop in response to increasing awareness and understanding of users.

A soil water application (status: red) has not been developed or designed, although there are relevant applications and web sites available for comparison. Application design requires careful analysis of the position of soil water forecasts within the existing ecosystem of decision support tools and data services. Design considerations may even be more important to adoption than reliable and accurate forecasts.

Understanding of farmer decision making (status: amber) is at a moderate level, although it is fragmented. Research on the design, infrastructure, and application of farm decision tools is very active, with a lack of standard approaches and methodologies. How and which decisions are supported and made on farm will change in future with technology advances such as cloud computing. As above, careful consideration of how farmers make decisions may be more important than the production of reliable and accurate forecasts.

Ad-hoc manual processes for feedback (status: red) are available. Well-structured, automated methods need to be developed.

\subsection{Research}

Climate forecasting (status: green) research is well advanced and ongoing. Current operational services using coupled ocean-atmospheric modelling produce daily ensemble (probabilistic) forecasts over a $250 \mathrm{~km}$ grid out to 270 days ahead, with significantly diminishing skill (accuracy) beyond about 3 months. Resolution will be increased to $\sim 60 \mathrm{~km}$ in the next two years, with associated increases in skill. Research into downscaling is relatively mature, with good results shown for reducing and correcting errors in the probabilistic structure of rainfall.

Monitoring of soil water (status: green) involves two distinct approaches: use of satellite data to provide estimates of soil water at broad scale, and in-situ monitoring of point-scale soil water content. Both approaches are well advanced and have a number of standard techniques and methodologies. For satellite data, research over the recent years has produced techniques to reduce biases and correct errors in translating satellite measurements to soil water estimates. Long term (eg 5-15 years) data are available for hindcasts and 
calibration, and assimilation methods are available to support near real-time estimates, albeit with limitations in extent, resolution and frequency.

There are two basic approaches to predicting agricultural soil water (status: red) - gridded land surface schemes and point-scale agricultural production models. The water balance fundamentals of these models are similar. Soil water is a modelled component of land surface schemes used for climatological modelling. The Bureau operates different models for different climate and water forecasting and assessment needs, each with soil water. The ability of these models to produce credible values of plant-available water through soil columns of varying depth is not known. The best use of probabilistic forecasts based upon ensembles is also not known. A number of point scale models exist that are capable of predicting soil water when driven by forecast rainfall and temperature, and are extensively used in decision support systems. Significant work has gone into water balance models that exist in models such as APSIM. Most do not actively assimilate remotely sensed data to provide updated state conditions necessary for good soil water forecasting. Also, most rely on historic climatology and use antecedent rainfall and statistical models to predict future yield. Recent work has been undertaken to test their performance when forced by climate forecast ensembles.

Local soil properties (status: amber) are needed to support downscaling of forecasts and to increase accuracy and reliability for farmers. The research challenge is reconciling broad scale datasets used for generic properties (e.g. ASRIS (http://www.asris.csiro.au), APSOIL (http://www.apsim.info/Products/APSoil.aspx) with the local data. This will likely need high quality local/farmer input, although the sensitivity of the soil water forecast to local soil data will also need to be analysed to determine the value of the extra effort to include local data. At a broad scale there may also be opportunities to infer better model soil properties from remotely sensed data.

\subsection{Development and maintenance}

Reliable ongoing development and maintenance of climate forecasting systems (status: green) is provided by the Bureau.

Both of the soil water model (status: green) approaches described above are well established in terms of development and maintenance. Issues such as code standards, performance, security, version control, update cycles, bug fixing and end-of-lifing old versions are undertaken within a controlled environment within which integration of new soil water approaches would only pose a moderate challenge.

Although the science and methods for data assimilation into land surface and hydrological models are moderately well established, there are no operating systems that focus on gathering soil water observations (status: red) and assimilating (status: red) these into models. The extent to which existing assimilation systems would need to be modified or extended to incorporate corrected soil water observations in unknown. There is also a lack of operational networks for ongoing assessment of profile soil moisture forecasts.

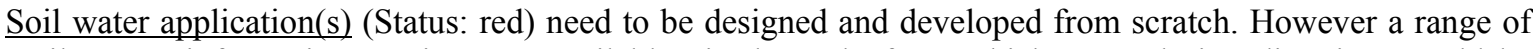
'soil water' information services are available via the web, from which some design directions could be gleaned.

\subsection{Operational services}

Climate forecast (status: green) systems are run operationally in well maintained systems. Seasonal-scale climate models are run weekly as daily ensemble (probabilistic) forecasts over a $250 \mathrm{~km}$ grid out to 270 days ahead, with significantly diminishing skill (accuracy) beyond about 3 months, producing public forecasts at monthly scales for the three months ahead. Over the next two years, grid sizes for operational services will reduce from $\sim 250 \mathrm{~km}$ to $\sim 60 \mathrm{~km}$, with associated improvements in performance and accuracy.

There are no soil water forecast systems (status: red) in operation, and service level requirements are unknown. Similarly, no soil water forecast apps (status: red) are available - in fact, depending upon information delivery approach from soil water forecast model to users, this element may not be needed.

Finally, no soil water observation assimilation (status: red) is taking place, although operational systems are available which are assimilating a range of potentially relevant remotely sensed products.

Thus, a significant portion of the required components exist in the operational environment, while others lie more within the realms of research, requiring a strategic approach to bridge the gap between research and operations. 


\section{FUTURE STRATEGIC OPTIONS}

Three alternative strategies for researching, developing and delivering soil water forecasting services are given below. These vary more in timing and effort, rather than nature, so it is possible that a successful approach may change gears from one strategy to another as opportunities arise and circumstances vary. The three strategies are:

- Incremental path - this starts by pulling together the best of what is available now to deliver user value early, then operates through agile iterations of service improvement supported by end-user analysis and feedback. The approach would be small scale at first, based upon ad-hoc collaboration directed towards aspirational goals

- $\quad$ Targetted path - this approach selects a user (individual, region, industry sector or enterprise type), and undertakes a full pilot implementation of a soil water forecasting service. This is then leveraged to a national scale service encompassing other regions and/or industry sectors. This would require a funded collaboration with the selected user, with specific, measureable and timely outcomes relative to funding and resources.

- Audacious path - this involves execution of a national-scale project that brings together multiple collaborators and disciplines to deliver an authoritative national service. This would require a much higher level of funding over a much shorter time than the above strategies, with significant earlier benefits to multiple agricultural industries.

Thus, by leveraging the modelling, monitoring and remote sensing research and development of the past decade, and combining this with existing operational services and approaches, it is possible that Australia will soon be on the path towards operational forecasting of agricultural soil water. Recent Australian Government initiatives, such as the National Water Use in Agriculture Research, Development and Extension Strategy 2015 and the $2^{\text {nd }}$ round of the Rural R\&D for Profit programme, provide opportunity to seek funding to pursue the approach outlined here.

\section{ACKNOWLEDGMENTS}

The authors acknowledge the significant input provided to this work by the attendees at the "Agricultural Soil Water R\&D - Observations and Outlooks" workshop held at The University of Melbourne, February 17-18, 2015. We also acknowledge the input of farmer workshops organised in collaboration with the Birchip Cropping Group (October 17, 2014), the Redesdale/Kyneton Lamb Graziers Discussion Group (May 21, 2015), and the Holbrook Landcare Network (August 21, 2015).

\section{REFERENCES}

Australian Bureau of Statistics, 2015. Value of Agricultural Commodities Produced, Australia, 2013-14. Australian Bureau of Statistics,.

CABLE Community, 2015. CABLE: The Community Atmosphere Biosphere Land Exchange Model.

Commonwealth of Australia, 2015. Agricultural Competitiveness White Paper: Canberra, p. 141.

Crow, W.T., Berg, A.A., Cosh, M.H., Loew, A., Mohanty, B.P., Panciera, R., de Rosnay, P., Ryu, D., Walker, J.P., 2012. Upscaling sparse ground-based soil moisture observations for the validation of coarse-resolution satellite soil moisture products. Reviews of Geophysics 50(2) $20 \mathrm{pp}$.

Hafeez, M., Frost, A., Vaze, J., Dutta, D., Smith, A., Elmahdi, A., 2015. A new integrated continental hydrological simulation system. An overview of the Australian water resource assessment modelling system (AWRAMS). Water. Journal of the Australian Water Association 42(3) 75-82.

Nemani, R.R., Keeling, C.D., Hashimoto, H., Jolly, W.M., Piper, S.C., Tucker, C.J., Myneni, R.B., Running, S.W., 2003. Climate-Driven Increases in Global Terrestrial Net Primary Production from 1982 to 1999. Science 300(5625) 1560-1563.

Smith, A.B., Walker, J.P., Western, A.W., Young, R.I., Ellett, K.M., Pipunic, R.C., Grayson, R.B., Siriwardena, L., Chiew, F.H.S., Richter, H., 2012. The Murrumbidgee soil moisture monitoring network data set. Water Resources Research 48(7) 6pp.

Su, C.H., Ryu, D., 2015. Multi-scale analysis of bias correction of soil moisture. Hydrol. Earth Syst. Sci. 19(1) 17-31.

The Collaboration for Australian Weather and Climate Research, 2015. ACCESS: a coupled climate and earth system simulator. 